\title{
Gêneros textuais, tipos de discursos e operações psicolingüísticas $^{1}$
}

\author{
Jean-Paul Bronckart \\ Universidade de Genebra
}

\section{Résumé}

L'article de Jean-Paul Bronckart est centré sur le problème controversé du classement des textes en le situant dans le cadre de la psychologie du langage et dans le cadre théorique de l'interactionisme social. La multiplicité et l'hétérogénéité des critères de classement et de nomenclature ont abouti à des classements homogènes, intermédiaires et hétérogènes. L'auteur part de considérations intermédiaires sur la notion de genre et sur les problèmes de classement et présente, sous une forme résumée, quatre thèses lapidaires des fondements du cadre de la psychologie interactioniste sociale. Un modèle de production textuelle est suggéré à partir du statut psychologique des textes empiriques et des opérations psycholinguistiques qui y sont sous-jacents. Une typologie centrée sur quatre entités basiques relève de ce modèle, nommé "archétypes discursifs": discours interactif, discours théorique, récit et narration. L'auteur tient à montrer que la compréhension du fonctionnement des textes est essentielle, visà-vis d'une lecture qui envisage une approche pédagogique. 


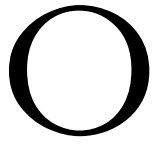

objetivo geral deste artigo é fornecer alguns elementos de reflexão sobre o problema da classificação dos textos e, mais especificamente, da classificação das diferentes espécies de textos do francês contemporâneo. A elaboração de uma tal classificação constitui uma tarefa difícil (desesperadora mesmo, diriam alguns), mas com a qual são, entretanto, inevitavelmente confrontados todos aqueles que, como no nosso caso, tentam contribuir para o desenvolvimento de uma teoria da aquisição da linguagem, ou ainda contribuir para rediscutir novas formas de didática do texto. Nos dois casos impõe-se abordar o problema dos gêneros ou tipos de textos: no primeiro, trata-se de conceituar a diversidade das formas de produção verbal que o aprendiz de uma língua teria que dominar; no segundo, de definir o programa e a progressão pedagógica que deveriam sustentar as abordagens do ensino explícito dos textos.

Nesta enésima discussão do problema da classificação, adotaremos entretanto um ponto de vista duplamente marginal; primeiramente, porque nossa abordagem decorre da psicologia da linguagem, mais que da lingüística ou das teorias da literatura; depois, porque, no próprio quadro daquela disciplina, essa abordagem se baseia numa tomada de posição epistemológica minoritária, a do interacionismo social.

\section{ASPECTOS DO PROBLEMA DOS GÊNEROS E DOS TIPOS}

Como todo mundo sabe, pelo menos desde a Antigüidade grega, tendo em vista a evidente heterogeneidade do "mundo dos textos", foram abundantes as propostas de categorização, e, a 
começar por Aristóteles, numerosos importantes pensadores ocidentais deram sua contribuição para a construção do edifício. Entretanto esse edifício permanece ainda hoje sempre instável, no sentido de que nenhuma classificação conseguiu se impor e de que nenhuma síntese verdadeira sobre a diversidade das propostas existentes pôde ser elaborada. Dois exemplos confirmarão esse fato.

No seu Dictionnaire encyclopédique des sciences du langage, no verbete gênero, DUCROT \& TODOROV (1973) reconhecem primeiramente essa impossibilidade de síntese, para em seguida se limitarem ao enunciado de algumas categorizações gerais. Em primeiro lugar, a oposição prosa-poesia, que eles não têm dificuldade em recusar, mas que permanece subjacente às distinções que comentam a seguir, uma vez que elas dizem respeito somente aos gêneros "poéticos" (este adjetivo parecendo funcionar como um sinônimo de "literário"). Esses autores retomam em particular a tripartição que, de Diomedes a Goethe, distingue os gêneros lírico, épico e dramático. Sem na verdade entrar no mérito sobre uma tal classificação, que foi comentada por numerosas vozes mais autorizadas que a nossa, formularemos entretanto duas observações.

A primeira diz respeito à multiplicidade e à heterogeneidade de critérios que são utilizados para fundamentar a própria tripartição. O épico (ou a epopéia) pode ser definido como "uma obra na qual autor e personagens têm igualmente direito à palavra" (Diomedes); para Goethe, é uma forma poética "que narra claramente", o que pôde ser reinterpretado em termos enunciativos como "uma obra que se refere ao ele"; para Jakobson, é um gênero no qual o fio condutor é (além da terceira pessoa) o tempo passado; para outros autores ainda, essa forma textual tem como objetivo suscitar no leitor uma "visão de conjunto" de uma situação, etc. O efeito a ser produzido no destinatário, o tipo de ato realizado pelo enunciador, o tipo de mobilização dos protagonistas da enunciação, o modo de estruturação temporal, e ainda a forma da produção, seu suporte material, etc., são igualmente critérios susceptíveis de concorrer para a definição de um gênero, mas que, pelo seu número, sua diversidade 
e sua falta de hierarquização interna, tornam, de fato, a própria noção inapta a qualquer operacionalização (notadamente para os fins psicológicos e didáticos evocados mais acima).

$A$ segunda observação diz respeito às próprias nomenclaturas de "gênero", de "forma", de "tipo" e ainda de "modo". VIËTOR (1986), por exemplo, contesta o fato de que as três entidades que acabam de ser evocadas constituam gêneros, porque elas não são definíveis com base em critérios propriamente linguageiros. Para esse autor, trata-se no caso de três "atitudes fundamentais do ser humano diante da realidade, atitudes para assegurar o domínio da realidade na ação e na reação" (1986, p.11). Essas categorias corresponderiam, portanto, a iguais "formas da experiência humana" e teriam, em conseqüência, um estatuto psicológico. Ao contrário, seriam as subdivisões atestáveis de cada uma daquelas formas (para o épico, por exemplo, a novela, o romance, a narração histórica, etc.) que constituiriam gêneros, definíveis, agora sim, com base em critérios decorrentes de sua modalidade de realização linguageira concreta. Estendendo esse esclarecimento terminológico, DUCROT \& TODOROV (1973) propõem uma distinção entre gênero e tipo com característica essencialmente metodológica. Diante do universo de textos concretos em um período histórico dado, eles consideram que uma primeira abordagem, de observação e de indução, permite delimitar gêneros diferentes, mesmo quando as fronteiras entre esses gêneros permaneçam permeáveis. Sobre essa base, uma segunda abordagem, de caráter dedutivo, permitiria então postular as regras e as características lingüísticas definidoras de um tipo: em princípio o tipo não seria jamais realizado por um exemplar de texto concreto, mas constituiria uma espécie de modelo teórico subjacente a cada gênero.

O segundo exemplo retoma uma das numerosas "tipologias de tipologias" elaboradas recentemente pelos didaticistas, no caso em questão aquela formulada por PETITJEAN (1989). O objetivo deste tipo de abordagem é de comparar as diversas classificações de textos, quaisquer que sejam eles (ou seja, não exclusivamente "literários") propostas no curso das últimas décadas. Fundamentando-se no 
estatuto de critérios utilizados para a classificação, Petitjean distingue três conjuntos de abordagens.

Em primeiro lugar, as classificações "homogêneas", que se baseiam na aplicação de uma única categoria de critérios, decorrente um mesmo campo disciplinar. Nesse primeiro grupo se inscreveria a tipologia de WERLICH (1975), por exemplo, que se baseia nos "procedimentos cognitivos" especificamente mobilizados por um texto: percepção do espaço para a descrição, percepção do tempo para a narração, etc. Igualmente se inscreveria a tipologia de ADAM (1985, 1987), baseada em um critério exclusivamente lingüístico, neste caso sobre a forma de seqüencialidade ou de "plano" que um texto exibe (planos injuntivo, argumentativo, narrativo, etc.).

As classificações "intermediárias", em seguida, que colocam em correspondência uma categoria de critérios de ordem pragmática e uma ou diversas categorias de critérios de ordem lingüística, considerando-se as marcas lingüísticas mais ou menos dependentes diretamente dos critérios pragmáticos ativados. Nessa segunda tentativa, somente uma rede de fatores pragmáticos seria privilegiada: o modo enunciativo, a intenção comunicativa ou ainda as condições sociais de produção. Certamente, estão elencadas nesse segundo conjunto as propostas de Benveniste, aquelas herdadas de Bakhtin, bem como aquela que nós mesmos formulamos em Le fonctionnement des discours (1985).

As classificações "heterogêneas", enfim, distinguir-se-iam das precedentes pela utilização simultânea de diversas redes de critérios pragmáticos (enunciação, estratégia ilocutória, conteúdo temático, etc.) colocados em correspondência com as unidades lingüísticas. Entre as múltiplas classificações decorrentes dessa terceira perspectiva, Petitjean assinala notadamente aquela elaborada apor CHARAUDEAU (1983).

No mesmo artigo, Petitjean sugere que as classificações que se baseiam em critérios homogêneos ou dominantes delimitam "tipos" ("tipos de textos" para o primeiro grupo, "tipo de discurso" para o segundo), enquanto que as classificações que utilizam séries heterogêneas de critérios visam à delimitação de "gêneros" de textos. 


\section{ALGUMAS CONSIDERAÇÕES INTERMEDIÁRIAS}

A primeira consideração consistirá em admitir que todo membro de uma comunidade lingüística é confrontado com um universo de textos "já vistos", universo organizado em "gêneros" empíricos e históricos, ou seja, em formas de organização concretas que se modificam com o tempo. A confrontação com esses gêneros preexistentes produz nos leitores um certo conhecimento intuitivo de suas regras e propriedades específicas, conhecimento de senso comum que JAUSS (1970) qualificou de maneira bastante feliz de "horizonte de espera". Essas regras e propriedades constituem, então, um processo de apropriação que, como todo mecanismo de aprendizagem social, se traduz quase necessariamente em modificações, em desvios e em reorganizações dessas mesmas regularidades. Em uma outra escala, talvez, os gêneros e seus usuários estejam na mesma relação genética e dialética existente entre o sistema de uma língua natural e seus usuários.

Face a essa situação, o primeiro problema que se coloca ao teórico do texto é de ordem metodológica: para qualificar os gêneros e eventualmente identificar os tipos que lhes estão subjacentes, somente se pode partir daquilo que já está disponível, ou seja, daqueles gêneros já mencionados na primeira consideração. Em outros termos, para se elaborar uma conceituação dos gêneros, devese dispor preliminarmente de um conhecimento do que eles são, e não é possível escapar dessa circularidade metodológica. O fato de tal circularidade ser, entretanto, comum entre as ciências humanas, não nos parece por isso colocar problemas incontornáveis. A partir de um universo de textos intuitivamente classificados em gêneros, é possível proceder a um estudo empírico de suas características (lingüísticas, principalmente) e formular um primeiro modelo de regras que as regem. A comparação entre modelos pode fazer aparecer parentescos ou divergências não observadas à primeira vista; regras relativas ao funcionamento de certas unidades podem ser deduzidas de novas regras; dessa maneira se elaboram "modelos de gêneros" ou "gêneros teóricos" cuja validade pode ser testada por 
um retorno aos dados empíricos, podendo esse processo de teste de hipóteses se estender ao infinito. Não há, na realidade, em tal empreitada, nada que difira fundamentalmente das metodologias de interpretação dos comportamentos adotadas notadamente pela psicologia e pela sociologia. E é por essa razão que nós não podemos manter a distinção tipo/gênero proposta por Ducrot e Todorov: a teorização de um gênero empírico não produz um tipo, mas um "gênero teórico" ou "modelo de gênero".

Contestaremos também as condições de uso dos termos "tipo" e "gênero" propostas por Petitjean. Primeiramente, parece que a denominação "tipo de texto" é bem pouco apropriada para as categorias elaboradas por Werlich e Adam. No primeiro caso, em razão do estatuto psicológico (ou pré-lingüístico) dos critérios adotados, não pode se tratar de "tipos de textos", mas de tipos de processos cognitivos, ou melhor, de tipos de ações. No segundo caso, como assinala o mesmo ADAM (1987), as seqüencialidades não caracterizam (a não ser acidentalmente) os próprios textos, mas sobretudo suas partes constitutivas; as seqüências são formas específicas de organização de enunciados, que se combinam entre elas de múltiplas maneiras para dar lugar a um texto propriamente dito. Contestaremos além disso a distinção colocada por Petitjean entre "tipos de discursos" e "gêneros de textos", na medida que, à exceção talvez de Benveniste, a maior parte das classificações qualificadas de intermediárias permitem, de fato, intervir séries de critérios heterogêneos. O estudo de Petitjean nos parece na realidade confundir os níveis de análise. Uma coisa é constatar a heterogeneidade dos critérios pelos quais são habitualmente definidos os gêneros históricos (como acabamos de fazer após tantos outros) e propor eventualmente modelos de cada um desses objetos heterogêneos; outra coisa é tentar identificar, atravessando as nebulosas de gêneros, estruturas de regras e de propriedades que autorizariam falar de tipos, e, nesse segundo caso, nada indica a priori que os critérios definidores desses tipos não possam ser eles mesmos heterogêneos. 
A identificação de eventuais tipos nos parece requerer, antes de tudo, uma tentativa de comparação de características contextuais e propriamente lingüísticas de diferentes gêneros empíricos num dado estado de língua. Essa identificação requer em seguida a construção de um modelo teórico para a confecção do qual o maior desafio nos parece ser o da hierarquização ou da organização de diferentes séries de critérios potenciais. Deveriam ser distinguidos em particular os critérios propriamente psicológicos (que dizem respeito ao tipo de ação engajada e ao tipo de processos cognitivos mobilizados), os critérios linguageiros (que dizem respeito às decisões que todo locutor deve tomar para realizar um ato de produção verbal), e os critérios lingüísticos (que dizem respeito às decisões a serem tomadas para realizar concretamente um texto no quadro das restrições de uma dada língua natural).

A essa condição de distinção de níveis se acrescenta aquela do caráter dialético de suas relações: seguramente, as configurações de parâmetros contextuais não exercem efeito mecânico sobre os textos; para uma dada situação, diversas soluções são sempre possíveis e a terceira tarefa do teórico é, então, a de tentar conceituar essa cascata de decisões sobre a qual repousa toda produção textual.

\section{O QUADRO DA PSICOLOGIA INTERACIONISTA SOCIAL}

Nos limites deste artigo, eu me limitarei a invocar alguns princípios centrais do interacionismo social, que deveriam ser suficientes para situar a perspectiva epistemológica na qual deveriam ser entendidas as propostas mais técnicas que virão a seguir. Esses princípios serão resumidos sob a forma de teses lapidares.

\section{Tese 1}

A consciência e as funções psíquicas superiores do homem (sobretudo pensamento e linguagem) são o produto da apropriação, em seguida da interiorização das propriedades das diferentes formações sociais nas quais todo ser humano se encontra necessariamente inserido. 


\section{Tese 2}

Esse processo de apropriação se realiza no quadro estrutural que constitui a ação humana e por um meio privilegiado que é o das produções semióticas, em particular as produções verbais. Ao lado dessas características genéticas, a consciência humana é, em conseqüência, uma estrutura não somente histórico-social, mas igualmente acional e semiótica.

\section{Tese 3}

As duas unidades maiores de análise da psicologia são, conseqüentemente, as ações e os textos.

As ações são seqüências organizadas de comportamentos, isoladas no fluxo contínuo da atividade de um grupo, pelo mesmo fato de que elas são atribuíveis a um agente. A atribuição de uma ação a um agente decorre das avaliações sociais dos comportamentos em atividade nas sociedades humanas; é o ambiente social que atribui aos agentes intenções, razões, fins, etc. E o próprio agente, interagindo com (e participando) essas avaliações, constrói para si mesmo representações das modalidades de sua contribuição para a atividade do grupo; ele constrói para si, dessa maneira, representações de fins, de intenções e de razões que definem sua consciência da ação. A ação humana tem assim dois modos de existência encaixados: ela é primeiramente o produto das avaliações sociais da atividade de um grupo; ela é em seguida o produto da interiorização dessas avaliações num agente individual.

Os textos são seqüências organizadas de comportamentos verbais, orais ou escritos, que são atribuíveis a um agente singular, num contexto determinado de ação. Proporemos uma análise detalhada mais adiante.

\section{Tese 4}

As relações entre ações e textos podem ser descritas como relações de mediação: o texto é o mediador da ação. Mas este conceito de mediação toma pelo menos três significados diferentes. 
Inspirando-nos na noção do "agir comunicacional" proposta por HABERMAS (1987), consideraremos primeiramente que o estatuto mais fundamental das produções verbais (ou os textos) é de constituir uma atividade que permita assegurar, entre os interactantes, uma concordância sobre o que são as situações e as ações das quais eles participam. Mais precisamente, é por (e na) interação verbal que se constroem os sistemas de coordenadas abstratas (ou mundos representados) que definem o contexto das ações humanas. E é sobre a base desse conhecimento linguageiro dos mundos que são avaliadas as ações atribuídas a um agente. Em outros termos ainda, as produções textuais são o meio através do qual se constroem as representações sociais e racionais que permitem situar e julgar cada contribuição singular à atividade (ou a cada ação).

Essa atividade linguageira ilocutória é também (mas em segundo lugar) produtora de signos, quer dizer, de unidades formais com caráter locutório ou declarativo: no curso da produção, partes de produções sonoras (ou verbais) se acham regularmente colocadas em correspondência com partes de representações do mundo. Desde que elas são cristalizadas pelo uso, essas correlações delimitam os significantes e os significados próprios a uma língua. Por esse processo, grandes áreas de mundos representados se acham assim (re)codificados nos signos e nas estruturas de uma língua natural; o sujeito interioriza esse conhecimento verbal, e aquele conhecimento constitui, ele próprio, um filtro de seu acesso ao mundo.

Desde que, enfim, as atividades humanas mediatizadas por uma língua se desenvolvem e se diversificam, essa tende também a se especializar em formas de organização diferentes ou textos. Os textos são essas modalidades de estruturação da atividade linguageira pelas quais os aspectos ilocutório e locutório são integrados, que dizem o mundo ao agir no mesmo mundo. Seguindo Bakhtin, podemos distinguir os textos primeiros (ou livres), que manteriam uma relação "imediata" com as situações nas quais eles são produzidos, e os textos segundos (estandardizados, padronizados) que manteriam uma relação "mediática" com sua situação de produção. Enquanto 
os discursos primeiros seriam assim "estruturados à ação", os discursos segundos (narração, discurso teórico, etc.) se desligariam dela e seriam submetidos a uma estrutura própria, convencional, de natureza especificamente linguageira; eles próprios seriam "estruturados em ação". Como sugere RICOEUR (1986), no prolongamento da concepção aristotélica de mimesis, a elaboração dessas estruturas textuais poderia ser interpretada como uma empreitada pela qual os seres humanos propõem uma refiguração ou uma esquematização das ações humanas: os textos autônomos ou segundos propõem uma visão concordante do mundo e dos contextos de ação, que é dada a ser lida ou interpretada, e é nesse trabalho de interpretação que os sujeitos reconstroem em definitivo sua compreensão das ações das quais eles participam.

\section{ELEMENTOS DE UM MODELO DE PRODUÇÃO DE TEXTOS}

Em função do que foi dito até aqui, todo modelo de produção textual deve, por um lado, integrar a problemática da relação do texto com a ação (\$3) e, por outro lado, distinguir e hierarquizar os níveis de abordagem ou análise dos textos produzidos ( $\$ 2)$.

\subsection{O texto empírico e seu estatuto psicológico}

Neste primeiro nível, defendemos a hipótese de que todo texto empírico pode ser considerado como o produto da interação entre uma ação linguageira e um gênero histórico determinado.

\subsubsection{A ação linguageira}

Do ponto de vista psicológico, um texto singular, ou uma produção textual, constitui uma seqüência de comportamentos verbais que podemos isolar no decurso das atividades humanas; é nesse sentido que podemos falar de "ação linguageira", ou ainda de "ação que implica a linguagem”. Essa ação se desenvolve em uma situação (ou um contexto geral) que nos parece poder ser definida 
com a interveniência de quatro conjuntos de parâmetros não hierarquizados:

- A situação material da enunciação, com os parâmetros psíquicos que constituem o emissor e sua modalidade de produção (oral ou escrita), o recebedor eventual, bem como o espaço-tempo da produção.

- O quadro social no qual se desenvolve a produção, quadro que pode ser caracterizado pelo tipo de formação social mobilizada (instituição escolar, estrutura familiar, etc.) pelos papéis sociais que dela decorrem para o emissor (estatuto do enunciador) ou para o recebedor (estatuto do destinatário), bem como pelas relações de finalidade que se estabelecem entre essas duas entidades.

- O modo de relação entre ação linguageira e ação não linguageira, que permite distinguir as produções textuais estruturadas pela ação não linguageira (textos primeiros, de Bakhtin) e as produções textuais autônomas (textos segundos), produções essas que podem ser dialogais ou monologais.

- As representações do mundo mobilizadas para a produção, ou ainda os conjuntos de conhecimentos relativos aos temas que serão verbalizados, tal como eles estão disponíveis (e organizados) na memória do agente da ação.

Levando-se em conta essas quatro categorias de parâmetros, podemos definir diversas espécies de ações linguageiras, de um ponto de vista exclusivamente psicológico, ou seja, sem prejulgar de modo algum as características lingüísticas efetivas dos textos que serão produzidos. A título de exemplo:

Le 12 décembre 1993, dans le préau d'une école d'Yverdon (espace-temps de production) et dans le cadre de ses activités professionnelles (formation sociale: "École"), monsieur X (émetteur), assumant son rôle d'enseignant (énonciateur), s'adresse oralement à Mademoiselle Y (récepteur), ayant le statut d'élève (destinataire) pour la convaincre de s'inscrire à un cours de rattrapage (but).

(No dia 12 de dezembro de 1993, no pátio de uma escola de Yerdon (espaço-tempo de produção) e no quadro de suas atividades 
profissionais (formação social: "escola"), o senhor X (emissor), assumindo seu papel de professor (enunciador), se dirige oralmente à senhora Y (recebedor), tendo o estatuto de aluna (destinatário), para convencê-la a se inscrever num curso de recuperação (finalidade)).

Essa produção monologal não se articula com uma ação não linguageira.

\subsubsection{A interação com os gêneros históricos}

Para realizar essa produção, o emissor-enunciador dispõe de um conjunto de modelos, que não são nada mais que os gêneros em uso na língua francesa, ou mais precisamente, os conhecimentos que ele construiu a respeito desses gêneros. Em função de sua apreciação da situação da ação na qual ele se encontra, ele vai escolher o modelo de gênero textual que lhe parecerá o mais pertinente e o mais eficaz e vai realizar uma produção mais ou menos inspirada nesse modelo (e, portanto, mais ou menos conforme o mesmo). Esse processo de reprodução pode ser decomposto em uma série de escolhas ou de decisões, ou ainda de operações psicolingüísticas, que tentaremos descrever mais adiante.

\subsubsection{O texto empírico}

Todo exemplar de texto (ou texto empírico) pode então ser definido como uma entidade lingüística correspondente, por um lado, à unidade psicológica que constitui a ação linguageira, e elaborada, por outro lado, em interação com um dos modelos de gêneros disponíveis em um dado estado da língua.

\subsection{As operações psicolingüísticas}

Esse termo designa portanto as decisões que toma o emissorenunciador no quadro do processo geral de reprodução de um gênero, adaptado a uma situação de ação linguageira. Atendo-nos somente às produções decorrentes de ações autônomas e monologais, parece podermos distinguir três níveis de operações. 


\subsubsection{As operações psicodiscursivas gerais}

Essas operações seriam a priori universais, porque necessárias a toda produção textual, qualquer que seja a língua natural utilizada; elas consistem na constituição de um mundo discursivo, na escolha de uma forma de seqüencialidade e na escolha de um grau de implicação dos parâmetros da situação material da produção.

A constituição do mundo discursivo se apresenta essencialmente como uma decisão relativa ao modo de organização das representações do mundo solicitadas pela produção textual. Existem duas possibilidades gerais nesse domínio. As representações (de ações, de eventos, de estados ou de relações) (re)codificados num texto podem ser organizadas num mundo "colocado à distância" (ou "disjunto") daquele da interação social em curso. Nesse caso, em que essas representações se referem a fatos passados e atestados (da ordem da História), a fatos a acontecer, a fatos plausíveis ou puramente imaginários, tais fatos devem se articular a uma origem (espaço)temporal, que "marca" essa distância, eles são narrados como se tivessem acontecido. Quando as representações (re)codificadas em um texto não são assim colocadas à distância (quando elas são sem uma origem), elas se situam necessariamente no mundo da interação social em curso. Nesse caso, o texto não relata, mas expõe ("mostra", "exibe") estados, noções ou eventos "conjuntos", ou seja, acessíveis no mundo dos protagonistas da interação.

Quer nos situemos no mundo do narrar ou no mundo do expor, em razão das restrições técnicas da produção verbal humana, as representação do mundo são inseridas em proposições (ou relações predicativas) organizadas num eixo sucessivo. Seguindo ADAM (1985), postularemos a existência, para os textos monológicos autônomos, os únicos aos quais nos referimos aqui, de cinco grandes modalidades de organização de proposições, ou de cinco formas de seqüencialidade, que o autor qualifica de narrativa (preferiríamos dizer "cronológica"), de descritiva, de injuntiva, de argumentativa e de expositivo-explicativa. Essas "seqüências" constituem o produto da (re)organização dos conhecimentos disponíveis na memória, que se torna necessária tendo em vista a linearidade de toda produção linguageira. 
No que se diz respeito à implicação dos parâmetros da situação material de produção, podemos distinguir duas possibilidades extremas. O emissor-enunciador pode integrar no seu texto referências explícitas aos parâmetros do ato de produção (remeter ao locutor, ao interlocutor, ao espaço ou ao tempo de produção). Nesse caso, elementos dessa situação material serão, conseqüentemente, "implicados" no texto e constituirão uma parte de seu conteúdo. Para interpretar completamente um tal texto, será portanto necessário conhecer tais condições de produção. Mas o emissor-enunciador pode também construir seu texto sem fazer nenhuma referência explícita aos parâmetros da situação de produção. Nesse caso, o texto é "autônomo" em relação a essa situação, e sua interpretação não requer nenhum conhecimento da mesma. Entre essas duas possibilidades extremas existem, evidentemente, diversas possibilidades intermediárias.

De Benveniste a Adam, um bom número de classificações de discursos e/ou de textos fazem, de fato, apelo a essas três ordens de decisão, e as variações observadas se enquadram essencialmente na hierarquização que aqui é proposta. De nossa parte, privilegiamos as decisões relativas ao mundo e à implicação da situação de produção, que cruzamos, resultando num quadro de dupla entrada com a proposta de quatro entidades que chamamos de arquitipos ${ }^{2}$ discursivos.

Relação com o mundo

Conjunção Disjunção

Relação

interativa

Implicação Discurso interativo

Relato interativo

com

a

situação

Autonomia Discurso teórico

Narração

Na medida que privilegia as seqüencialidades, Adam objetiva evidentemente uma tipologia diferente, e outras formas de classificação são ainda possíveis e legítimas visto que as três ordens de decisão 
invocadas estão, evidentemente, em forte interação. A título de exemplo, para os textos que expõem (relação de "conjunção"), podemos considerar que todos os graus de implicação da situação de enunciação são possíveis e que os textos estão escalonados sobre um continuum, de tal maneira que o discurso verdadeiramente autônomo (ou teórico) acabe se constituindo num limite raramente (ou jamais) atingido. Ao contrário, sobre o eixo dos textos que narram, a bipartição parece mais clara, quer a situação de enunciação esteja implicada, quer não. Podemos notar igualmente que as seqüências cronológicas e descritivas são particularmente adaptadas ao mundo narrado, e as argumentativas ao mundo exposto, etc.

Entretanto, para comentar mais detalhadamente as propostas de classificação e seu estatuto, é conveniente retomar, antes, a segunda categoria de operações psicolingüísticas.

\subsubsection{As operações psicodiscursivas específicas}

Como indicamos, as operações que acabam de ser descritas têm um estatuto universal; elas dão conta de decisões relativas à elaboração do mundo discursivo, à organização seqüencial das representações e à relação com a situação da enunciação, que todo locutor de uma língua natural é capaz de tomar. E os próprios arquitipos que podemos identificar com base em uma tal análise apresentam portanto também eles um caráter universal ou psicológico. Essas decisões são, então, teóricas, pelo fato de que elas não permitem predizer inteiramente (ou por elas mesmas) as características lingüísticas efetivas que poderemos observar nos segmentos de textos concretos nos quais elas ocorrerão. Tomemos um exemplo: para relatar um evento fictício (a invasão da Espanha pelas forças armadas da Suíça), um enunciador deverá colocar esse conteúdo à distância (estabelecer uma origem) e vai também abstrair-se da situação concreta de produção na qual ele se encontra; em outras palavras, ele vai "entrar numa narração". Mas, apesar do caráter isolado dessa decisão, os segmentos de texto concretos que ele é 
capaz de produzir poderão, como todo mundo sabe, apresentar numerosas diferenças e se caracterizar, em francês, seja pela presença da dupla de tempos passado simples/imperfeito, seja pelo emprego do presente bistórico. Essas variações na realização lingüística de um mesmo arquitipo remetem a dois fenômenos distintos. Primeiramente, no quadro de uma mesma língua natural, diversos paradigmas de formas podem estar em concorrência para a realização de um mesmo arquitipo (muitos subsistemas de tempos, para ficar no nosso exemplo) e a escolha entre essas variantes se fundamenta em outras decisões além daquelas evocadas até aqui (ver mais adiante as operações psicotextuais). Em segundo lugar, é evidente que a concretização lingüística de um arquitipo depende de características da língua natural utilizada. Restringindo-nos ao exemplo dos tempos verbais, para realizar o arquitipo narrativo, como também o arquitipo relato interativo, o alemão dispõe de uma só forma de base, o praeterit; no catalão, ao contrário, às formas (globalmente) equivalentes ao passado simples, ao passado composto e ao imperfeito da língua francesa, se acrescenta um perfeito perifrástico, e essas formas podem então se distribuir de maneira diferenciada nos dois arquitipos. Os arquitipos se realizam, portanto, no quadro das possibilidades de "marcação" que dependem de uma língua natural e do estado histórico de valores atribuídos às unidades de um mesmo paradigma (história que não deixa de ter relação com aquela dos gêneros, mas não poderemos abordar esse problema interessante aqui).

Às operações psicodiscursivas gerais devem, conseqüentemente, estar associadas operações psicodiscursivas específicas, as quais, em função do inventário de meios de que dispõe uma língua natural, por um lado, marcam mais ou menos claramente as oposições entre arquitipos e, por outro, operam uma seleção entre as variantes possíveis na língua. É através dessas operações que os arquitipos teóricos se concretizam em tipos lingüísticos ou tipos de discursos. 


\section{Síntese intermediária}

Partimos de uma crítica clássica da noção de gênero, e da constatação da extrema diversidade de tipologias e da imprecisão do próprio conceito de tipo, para passar um tanto abruptamente a uma teoria da ação que se coloca como base de um modelo de produção linguageira, para cuja apresentação foram incidentalmente reintroduzidas as noções de tipos e de arquitipos. Agora é tempo de fazer um resumo e de tentar explicitar a significação que nossa análise confere a essas diferentes noções.

a) Admitimos que todo locutor está exposto a um universo de textos no qual ele conhece e reconhece intuitivamente essas galáxias de contornos muito tênues que constituem os gêneros históricos.

b) No quadro de um contexto de ação determinada, esse locutor pode se engajar em uma produção verbal, isto é, realizar uma ação linguageira ou unidade psicológica na qual a correspondente lingüística é o texto empírico.

c) A concretização deste texto empírico se baseia em processos de imitação, reprodução e/ou deformação de um dos gêneros históricos do qual o locutor tem um conhecimento prático. E os textos empíricos devem, pois, antes de tudo, ser analisados como exemplares de um gênero.

d) Os gêneros são formações sócio-linguageiras fechadas (são gêneros de textos), organizadas segundo modalidades heterogêneas, em função de determinações heterogêneas; o que podemos, em conseqüência, é apenas descrevê-los.

e) Os gêneros articulam e combinam de diversas maneiras entidades que chamamos de "tipos". Um texto empírico pertencente a um gênero combina, portanto, através de modalidades de encaixe e de hierarquizações múltiplas, segmentos pertencentes a um determinado tipo.

f) O tipo pode ser tomado ao mesmo tempo como arquitipo psicológico ou como tipo lingüístico. Ele é arquitipo quando ele se baseia numa configuração de operações gerais (tal mundo, tal seqüencialidade, 
tal relação com a enunciação); é tipo lingüístico na medida que essas mesmas operações não são verificáveis a não ser através de sua formalização "em uma língua natural", formalização que explora o material específico e os valores históricos dos quais ele é portador.

g) O tipo é, portanto, uma entidade bifacetada, atestável sob o ângulo das operações de tratamento das situações de ação e sob o ângulo dos correspondentes lingüísticos dessas operações. O tipo se diferencia do gênero pelo fato de que implica uma possibilidade de identificação com base em suas propriedades lingüísticas; e é tipo de discurso pelo fato de que essas unidades são o traço, formalizado em língua natural, de operações de tratamento dos contextos de ação.

h) Mas o conjunto das unidades e regularidades lingüísticas observáveis num segmento de texto não pode ser imputado ao fato de pertencerem ao tipo. Por um lado, se certas configurações de unidades decorrem do tipo, sua distribuição interna e os valores que elas tomam decorrem de outras operações mais locais. Por outro lado, os conjuntos de unidades dependem de operações que se aplicam ao conjunto do texto, e "atravessam", portanto (sendo aí às vezes moduladas), os diferentes tipos que o constituem. São essas operações que nos resta mencionar.

\subsubsection{As operações psicotextuais}

Falando resumidamente, desse último nível decorrem, de uma parte, as operações de textualização (conexão, coesão nominal, coesão verbal, etc.) e, de outra parte, as operações de modalização.

Essas operações e suas formas de realização lingüística constituem o objeto de numerosas análises e eu me limitarei a formular duas observações a seu respeito.

Primeiramente, a grande parte dessas operações é gerida ao mesmo tempo no nível do texto e no nível dos discursos que a constituem. As unidades de conexão, por exemplo, contribuirão ao mesmo tempo para marcar as grandes articulações do texto 
(notadamente para assinalar as mudanças de tipo de discurso) e para marcar a seqüencialidade própria a um tipo. Alguns organizadores serão polivalentes, outros próprios a um tipo (ou tomarão valores próprios a um tipo). O mesmo acontece com as unidades que contribuem para a coesão nominal. Ao mesmo tempo relevaremos que as unidades relativas à modalização são geralmente geridas unicamente no nível do texto, enquanto as relativas à coesão verbal parecem quase exclusivamente geridas no nível do tipo de discurso.

É preponderantemente (mas não exclusivamente) no nível da combinatória dessas operações psicotextuais que se estabelecem as singularidades irremediáveis das produções textuais, ou que se desenham, em outros termos, as propriedades estilísticas do texto. Restringindo-nos sempre ao problema dos tempos verbais, é possível constatar que certos autores poderão redigir segmentos narrativos inteiros atendo-se somente ao emprego do imperfeito e do mais-queperfeito, sem jamais utilizar o passado simples (cf. PLAZAOLA \& BRONCKART, 1993, para um estudo de Simenon), produzindo dessa maneira um "efeito estilístico" preciso e deliberado.

\section{SE É NECESSÁRIO CONCLUIR...}

Às oito proposições da síntese intermediária poderíamos acrescentar que, se todo texto empírico decorre de um gênero, e que se esse gênero é constituído de tipos lingüísticos encaixados, os próprios tipos ficam obscurecidos pelo jogo de operações decorrentes da própria textualidade e pelo jogo de operações de intervenções modais puramente configuracionais.

E podemos, sobre essa base, colocar a questão de como tudo isso se aprende e de como tudo isso deverá ser ensinado. 


\section{NOTAS}

${ }^{1}$ Tradução de Rosalvo Gonçalves Pinto, doutorando em Lingüística pelo PosLin - Programa de Pós-Graduação em Letras: Estudos Lingüísticos - Faculdade de Letras / Universidade Federal de Minas Gerais.

${ }^{2}$ Nota do tradutor: o francês tem as formas archétype, cujo correspondente no português seria arquétipo, e architype, usada nesse contexto pelo autor, a qual estou propositadamente traduzindo por arquitipo.

\section{REFERÊNCIAS BIBLIOGRÁFICAS}

ADAM, J. M. Quels types de textes? Le Français dans le monde, n. 192, 1985. 1987. . Types de séquences textuelles élémentaires. Pratiques, n. 56, p. 54-79,

BRONCKART, J. P. Le fonctionnement des discours. Un modèle psychologique et une méthode d'analyse. Lausanne: Delachaux \& Niestlé, 1985.

Genres de textes, types de discours et opérations psycholinguistiques. Lyon: Voies Livres, 1996.

CHARAUDEAU, P. L'acte de langage comme mise en scène. In: Langage et discours. Paris: Hachette, 1983.

DUCROT, O.; TODOROV, I. Dictionnaire encyclopédique des sciences du langage. Paris: Seuil, 1973.

HABERMAS, J. Théorie de l'agir communicationnel I et II. Paris: Fayard, 1987.

JAUSS, H. R. Littérature médiévale et théorie des genres. Poétique, I, 1970.

PETITJEAN, A. Les typologies textuelles. Pratiques, n. 62, p. 86-125, 1989.

PLAZAOLA GIGER, I.; BRONCKART, J. P. Le temps du polar. Langue Française, n. 97, p. 14-42, 1993.

RICOEUR, P. Du texte à l'action: essais d'herméneutique II. Paris: Seuil, 1986.

VIËTOR, K. L'histoire des genres littéraires. In: GENETTE, G. et al. Théories es genres. Paris: Seuil, 1986. p. 9-35.

WERLICH, E. Typologie der Texte. Heidelberg: Quelle \& Meyer, 1975. 